\title{
Clinical Impact of Endoscopic Submucosal Dissection for Early Gastric Cancer
}

\author{
Takashi Kosaka $^{1}$, Masaki Endo ${ }^{1 *}$, Yousuke Toya ${ }^{1}$, Tomomi Mizutani ${ }^{1}$, Yukito Abiko ${ }^{1}$, \\ Norihiko Kudara $^{1}$, Masaaki Inomata ${ }^{1}$, Toshimi Chiba ${ }^{1}$, Yasuhiro Takikawa ${ }^{1}$, Kazuyuki Suzuki ${ }^{1}$, \\ Tamotsu Sugai ${ }^{2}$
}

\author{
${ }^{1}$ Department of Gastroenterology and Hepatology, Iwate Medical University School of Medicine, Morioka, Japan; ${ }^{2}$ Department of \\ Diagnostic Pathology, Iwate Medical University School of Medicine, Morioka, Japan. \\ Email: ${ }^{*}$ msendo@iwate-med.ac.jp
}

Received November $26^{\text {th }}, 2012$; revised December $28^{\text {th }}, 2012$; accepted January $6^{\text {th }}, 2013$

\begin{abstract}
Aim: The aim of this study was to examine the safety and efficacy of endoscopic submucosal dissection (ESD) for early gastric cancer based on approximately 10 years' experience. Methods: Endoscopic submucosal dissection was performed in 1272 patients with early gastric cancer (1657 lesions). We examined en bloc resection rate, curative resection rate, local recurrence rate, procedure time, and complications. Results: The overall en bloc resection rate was $98.6 \%$ for all lesions treated by ESD. The median procedure time of the operation was 54.3 minutes (range $5-632 \mathrm{~min}$ ). The incidence of positive horizontal and vertical margins was 3.8\% and $4.0 \%$, respectively. The incidence was $2.5 \%$ each for perforation and postoperative bleeding. There were no deaths related to ESD. Local recurrence was observed in 10 lesions $(0.06 \%)$. Conclusion: Since the procedure time and incidence of complications have been reduced, endoscopic submucosal dissection has been considered a standard treatment for early gastric cancer.
\end{abstract}

Keywords: Endoscopic Submucosal Dissection; ESD; Gastric Cancer

\section{Introduction}

More than 10 years ago, endoscopic submucosal dissection (ESD) was introduced as an endoscopic treatment for gastrointestinal intraepithelial neoplasia. There were initial concerns regarding its potential complications and long procedure time, but these problems have since been resolved [1,2]. ESD has been shown to be an effective treatment for cancers of the esophagus, stomach, and colon.

Endoscopic mucosal resection (EMR) has been widely used as an endoscopic treatment for gastric cancer since the 1990s. Its disadvantages included a high incidence of piecemeal resection and local recurrence. It was thought to be possible to expand the indications for endoscopic treatment based on the lymph node metastatic rates. However, en bloc resection of larger lesions required special skills. An IT knife (insulation-tipped diathermy knife), hook knife, and flex knife were developed for the en bloc resection of larger lesions, thus resulting in the widespread use of ESD.

The en bloc resection rate is very high for ESD. In addition, it has been reported to have better short-term out-

${ }^{*}$ Corresponding author. comes [3-6] compared with EMR [7]. However, outcomes of ESD from a few experienced endoscopists are not sufficient to establish ESD as a standard treatment. Since our institution is a university hospital, new practitioners are trained every year to perform ESD. ESD was introduced to our institution 10 years ago, and there are more than 20 practitioners who have performed this procedure. In addition, the total number of treated lesions has exceeded 1500 . We believe that it is valuable to analyze therapeutic outcomes obtained from such a large number of lesions and over a long period of 10 years. We examined the outcomes of ESD as a treatment for early gastric cancer, and herein describe its usefulness, and the clinical outcomes and complications.

\section{Patients and Methods}

\subsection{Patients}

ESD was performed in 1272 patients (1657 lesions) for early gastric cancer between June 2002 and March 2012 at our institution. There were 913 males and 359 females with a mean age of 70.6 years ( $\mathrm{SD} \pm 8.6)$. ESD was performed on lesions satisfying the expanded indications reported by Gotoda et al. [8] and those in the Japanese 
gastric cancer treatment guidelines [9] provided by the Japanese Gastric Cancer Association. The patients included those who strongly desired endoscopic treatment and those in a high risk group for general anesthesia due to decreased cardiovascular function. In our department, the indications for endoscopic treatment for early gastric cancer include: differentiated gastric cancer (well and moderately differentiated adenocarcinoma and papillary adenocarcinoma) and mucosal cancer without ulcer findings, irrespective of the tumor size, mucosal cancer with ulcer findings $<30 \mathrm{~mm}$ in diameter, and minute $(<500$ $\mu \mathrm{m}$ from the muscularis mucosae) submucosal invasive cancer $<30 \mathrm{~mm}$ in size or undifferentiated adenocarcinoma (poorly differentiated adenocarcinoma or signetring-cell carcinoma) and mucosal cancer without ulcer findings $<20 \mathrm{~mm}$ in diameter (Table 1). The following were excluded based on an analysis related to the follow-up: patients with lesions outside the indications, patients with gastric remnants, patients with gastric tubes and metachronous lesions. Written informed consent was obtained from all patients before ESD.

\subsection{The ESD Procedure}

Before ESD, magnifying endoscopy with narrow band imaging (NBI) was performed as a preoperative examination. If lesions had ill-defined margins, biopsy samples were taken from the surrounding tissues to determine the areas negative for cancer. If the extent of a lesion was well-defined by magnifying endoscopy, the extent on the day of ESD was determined using white-light endoscopy and chromoendoscopy with indigo-carmine solution. A circumferential marking was made $5 \mathrm{~mm}$ from the outer margin of the lesion using a flex knife [10] (KD-630L, Olympus, Tokyo, Japan) or dual knife (KD-650Q, Olympus, Tokyo, Japan). A local submucosal injection was performed using a mixture of glycerol and sodium hyaluronic acid [11] and a 25-gauge injection needle. An initial incision was made outside of the marking dots using a flex knife or dual knife. An IT knife [12,13] (KD-610L or KD-611L, Olympus, Tokyo, Japan) was inserted into the initial incision to make a mucosal incision, and the submucosal dissection was also performed using the IT knife. For sites with marked fibrosis, a dual knife, hook knife [14] (KD-620QR, Olympus, Tokyo, Japan), and SB knife junior type (MD-47703, SUMITOMO BAKELITE Co., Japan) were useful. An ICC200 or VIO 300D (ERBE Co., Tubingen, Germany) was used as a high frequency generator.

All patients were sedated by venous injection of 0.1 $0.2 \mathrm{mg} / \mathrm{kg}$ of midazolam and $15 \mathrm{mg}$ of pentazocine. If they were still alert or complained of any pain, then the doses were increased accordingly. Their vital signs were monitored carefully during the examination using a pulse oximeter, sphygmomanometer, and ECG monitor.

The procedure time was defined as the time from the completion of marking to the removal of the scope. Perforation was diagnosed endoscopically, or by the presence of free air on a plain abdominal radiograph or a computed tomography image. Postoperative bleeding was discovered by the presence of hematemesis, tarry stool, or a decreased hemoglobin level after all ESD procedures were completed and the endoscope was removed.

\subsection{Histopathological Evaluation}

The tumor site was divided categorized into one of three equal parts from the lesser to the greater curvature of the stomach. From proximal to distal, the areas were divided into the upper $(\mathrm{U})$, middle $(\mathrm{M})$, and lower $(\mathrm{L})$. Macroscopically, the classifications were elevated, and depressed or flat. The resected specimen was observed under a stereomicroscope and subsequently cut into $2 \mathrm{~mm}$ pieces. The histology was classified into differentiated adenocarcinoma (well and moderately differentiated ade-

Table 1. Indicated for ESD.

\begin{tabular}{ll}
\hline Guideline criteria & $\begin{array}{l}\text { Differentiated-type adenocarcinoma without ulceration, of which the depth of invasion is clinically diagno- } \\
\text { sis as mucosal cancer }(\mathrm{M}) \text { and the diameter is } \leqq 20 \mathrm{~mm} .\end{array}$ \\
\hline & Tumor size $>20 \mathrm{~mm}$, histologically of differentiated type, \\
& depth $\mathrm{M}, \mathrm{UL}(-)$, or \\
& Tumor size $\leqq 30 \mathrm{~mm}$, histologically of differentiated type, \\
& depth $\mathrm{M}, \mathrm{UL}(+)$, or \\
& Tumor size $\leqq 30 \mathrm{~mm}$, histologically of differentiated type, \\
& depth SM1, UL $(+)$, or \\
& Tumor size $\leqq 20 \mathrm{~mm}$, histologically of undifferentiated type, \\
& depth $\mathrm{M}, \mathrm{UL}(-)$.
\end{tabular}

SM1: $\leqq 500$ micron from the muscularis mucosae. 
nocarcinoma and papillary adenocarcinoma) or undifferentiated adenocarcinoma (poorly differentiated adenocarcinoma or signet-ring-cell carcinoma). The tumor size, depth of invasion, presence of ulcerative findings, lymphatic and vascular involvement, and tumor involvement in the horizontal and vertical margins were assessed.

\subsection{Definition of Curative Resection}

All piecemeal resection cases were established as cases with non-curative resection. If an incision was made into the specimen, the case was established as a non-curative resection case if the incision was made into the lesion. The case was considered to satisfy the criteria for curative resection if 1) an en bloc resection was performed, 2) histological indications and expanded indications were satisfied, 3) the horizontal margin was $1 \mathrm{~mm}$ or more, and there were at least 10 glandular ducts, 4) there were no cancer cells in the vertical margin in the deepest part of the resected specimen and no lymphatic or vascular involvement. If a lesion had mixed histology, its histological type was determined using the predominant histological type for each area [15].

\subsection{Follow-Up Schedule}

In all patients, endoscopy was performed to examine the post-resection ulcer one month after ESD. If patients had a Helicobacter pylori infection, its eradication was performed. Thereafter, an endoscopic examination was performed once a year, if the patients had lesions satisfying the indications for ESD in the aforementioned guidelines (guideline lesions) and if they had undergone curative resection. In cases of mucosal cancer, an endoscopic examination was performed six months later and one year later, if the patients had positive horizontal margins and had lesions satisfying the expanded indications (expanded-indication lesions). If local recurrence was not observed, endoscopy was performed once a year thereafter. The patients with expanded-indication lesions also underwent periodic abdominal ultrasound and abdominal CT examinations. If patients were followed up outside of our institution, we conducted an annual questionnaire survey of their primary care physicians. If the patients had not made hospital visits, they were contacted at their homes to confirm that they were alive and to encourage that they undergo examination.

\subsection{Statistical Analysis}

The significance of the differences in patient characteristics and clinicopathological features was determined using the $\chi^{2}$ test, or Student's t-test, as appropriate. A value of $\mathrm{p}<0.05$ was considered to be statistically significant.

\section{Results}

\subsection{Clinicopathological Features}

ESD was performed for gastric cancer in 1272 patients (1657 lesions) (Table 2). The location of the tumor was the $\mathrm{U}$ area in 234 lesions, the $\mathrm{M}$ area in 725 lesions, the $\mathrm{L}$ area in 659 lesions, the gastric remnant in 35 lesions, and the gastric tube in 4 lesions. Macroscopically, 885 lesions were elevated-type tumors and 772 lesions were depressed or flat-type tumors. The predominant histopathological type after resection was well-differentiated adenocarcinoma in 1459 lesions, moderately-differentiated adenocarcinoma in 137 lesions, papillary adenocarcinoma in 30 lesions, and poorly-differentiated adenocarcinoma or signet-ring-cell carcinoma in 31 lesions. When the depth of invasion was examined, 1477 lesions were mucosal cancer, 74 lesions were SM1 tumors $(<500$ $\mu \mathrm{m}$ from muscularis mucosae), 105 lesions were SM2 or deeper tumors, and 1 lesion was undiagnosable due to thermal degeneration. The final pathological diagnosis, including that of lymphatic and vascular involvement, was within the guideline criteria in 1082 lesions, was within the expanded indications in 398 lesions, and was outside the indications for endoscopic treatment in 177 lesions.

\subsection{Resectability and Curability of ESD}

The overall en bloc resection rate was $98.6 \%$ (Table 3) for all lesions treated with ESD. The median procedure time was 54.3 minutes (range 5 - $632 \mathrm{~min}$ ). The incidence rates of positive horizontal and vertical margins were $3.8 \%$ and $4.0 \%$, respectively, and these values included cases with undeterminable margins. Table 4 shows the clinical outcomes of the guideline lesions and expanded-indication lesions. The en bloc resection rate was $99.4 \%$ for the guideline lesions, $97.4 \%$ for the expanded-indication lesions without ulcers (expand, UL-), and $98.9 \%$ for the expanded-indication lesions with ulcers (expand, UL+). The curative resection rate was $97.3 \%$ for the guideline lesions, $82.0 \%$ for the expanded-indication lesions without ulcers (expand, UL-), and $88.2 \%$ for the expanded-indication lesions with ulcers (expand, UL+). The rate was significantly lower for the expanded-indication lesions compared with the guideline lesions $(p<0.001)$. The procedure time was significantly longer for the expanded-indication lesions compared with the guideline lesions $(\mathrm{p}<0.001)$. The horizontal margin was positive in $7.5 \%$ of the expanded-indication (expand, $\mathrm{UL}-$ ) lesions, i.e., lesions $20 \mathrm{~mm}$ or larger. As the lesion increased in size, the number of patients increased in whom the diagnosis of the extent of invasion was difficult, affecting the curative resection rate. There were 28 patients with non-curative resection of guideline lesions. During the post-treatment follow up (Figure 1), one of 
Table 2. Characteristics of the patients and tumors.

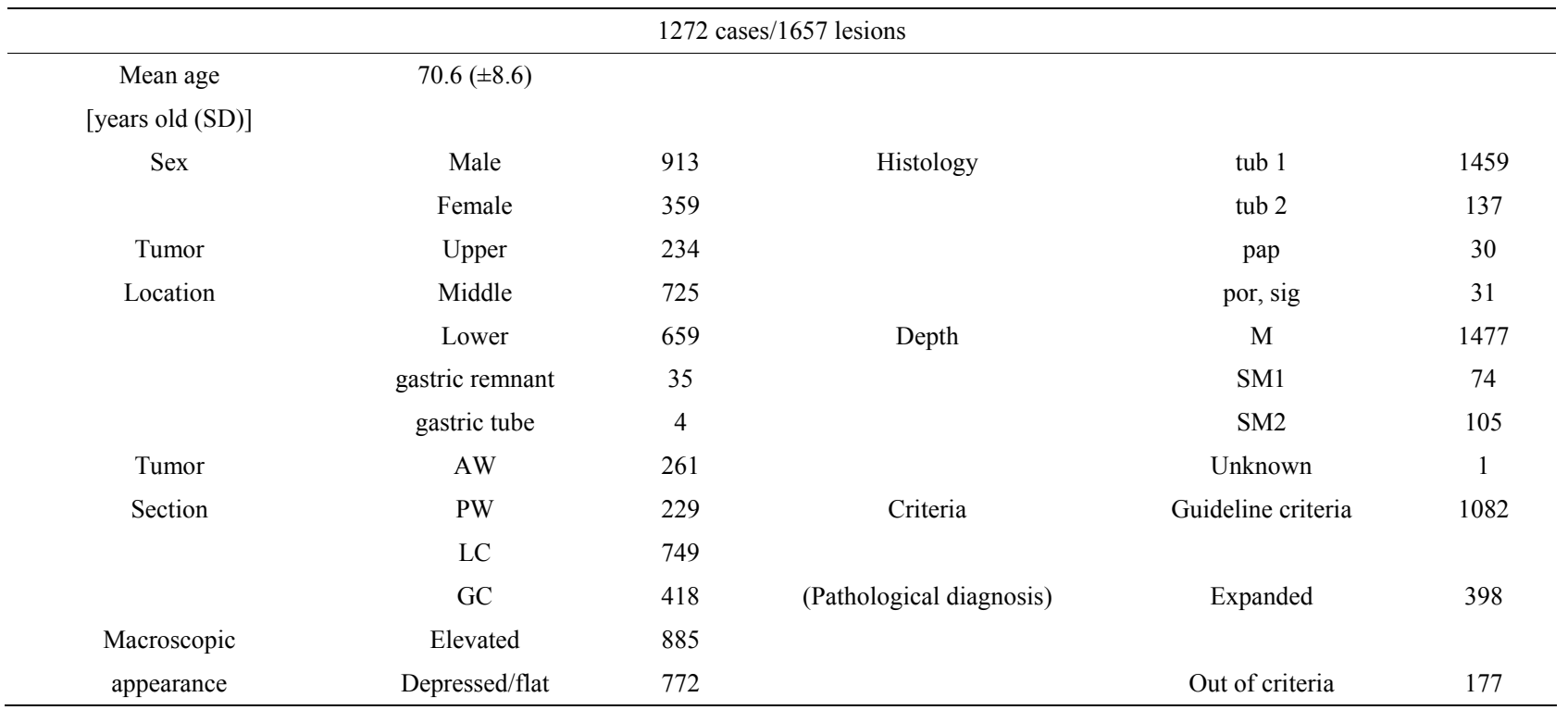

Table 3. Short-term outcomes of endoscopic submucosal dissection for early gastric cancers.

\begin{tabular}{cccc}
\hline & total $\mathrm{n}=1657$ & & \\
\hline En bloc resection & $98.6 \%(1633)$ & & \\
Curative resection & $84.7 \%(1403)$ & $\cdot$ Operation & $0.06 \%(1)$ \\
Post operative bleeding & $2.5 \%(41)$ & $\cdot$ IVR & $0.06 \%(1)$ \\
Perforation & $\cdot$ transfusion: $0.5 \%(9)$ & $\cdot$ Delayed & $0.24 \%(4)$ \\
& $2.5 \%(42)$ & & \\
Horizontal margin positive & & & \\
Vertical margin positive & $3.8 \%(63)$ & \\
Procedure time & $4.0 \%(67)$ & \\
(median/min) & $54.3(5-632)$ & & \\
Local recurrence & $0.06 \%(10)$ & \\
\hline
\end{tabular}

Table 4. Short-term outcomes of early gastric cancers lesions that met the guideline and expanded criteria.

\begin{tabular}{|c|c|c|c|c|}
\hline & \multirow{2}{*}{$\begin{array}{c}\text { Guideline criteria } \\
(\mathrm{n}=1082)\end{array}$} & \multicolumn{2}{|c|}{ Expanded $(\mathrm{n}=398)$} & \multirow[t]{2}{*}{ p-value } \\
\hline & & $\mathrm{UL}-(\mathrm{n}=305)$ & $\mathrm{UL}+(\mathrm{n}=93)$ & \\
\hline En bloc recection & $99.4 \%(1075)$ & $97.4 \%(297)$ & $98.9 \%(92)$ & 0.012 \\
\hline Curative resection & $97.3 \%(1053)$ & $82.0 \%(250)$ & $88.2 \%(82)$ & $<0.001$ \\
\hline Post operative bleeding & $1.8 \%(20)$ & $3.9 \%(12)$ & $4.3 \%(4)$ & NS 0.05 \\
\hline - transfusion & $0.2 \%(2)$ & $1.0 \%(3)$ & $2.2 \%(2)$ & \\
\hline - operation & & $0.3 \%(1)$ & $1.1 \%(1)$ & \\
\hline - IVR & & $0.3 \%(1)$ & & \\
\hline Perforation & $1.6 \%(17)$ & $4.3 \%(13)$ & $3.2 \%(3)$ & NS 0.42 \\
\hline - delayed & $0 \%$ & $1.0 \%(3)$ & $0 \%$ & \\
\hline - operation & $0 \%$ & $0.3 \%(1)$ & $0 \%$ & \\
\hline Other complications & $2.0 \%(22)$ & $3.6 \%(11)$ & $3.2 \%(3)$ & NS 0.25 \\
\hline Horizontal margin positive & $1.0 \%(11)$ & $7.5 \%(23)$ & $0 \%(0)$ & $<0.001$ \\
\hline Vertical margin positive & $0.8 \%(9)$ & $3.0 \%(9)$ & $0 \%(0)$ & $<0.01$ \\
\hline Procedure time & 41.7 & 70.2 & 81.8 & $<0.001$ \\
\hline (median/min) & $(5-315)$ & $(8-345)$ & $(15-415)$ & \\
\hline
\end{tabular}




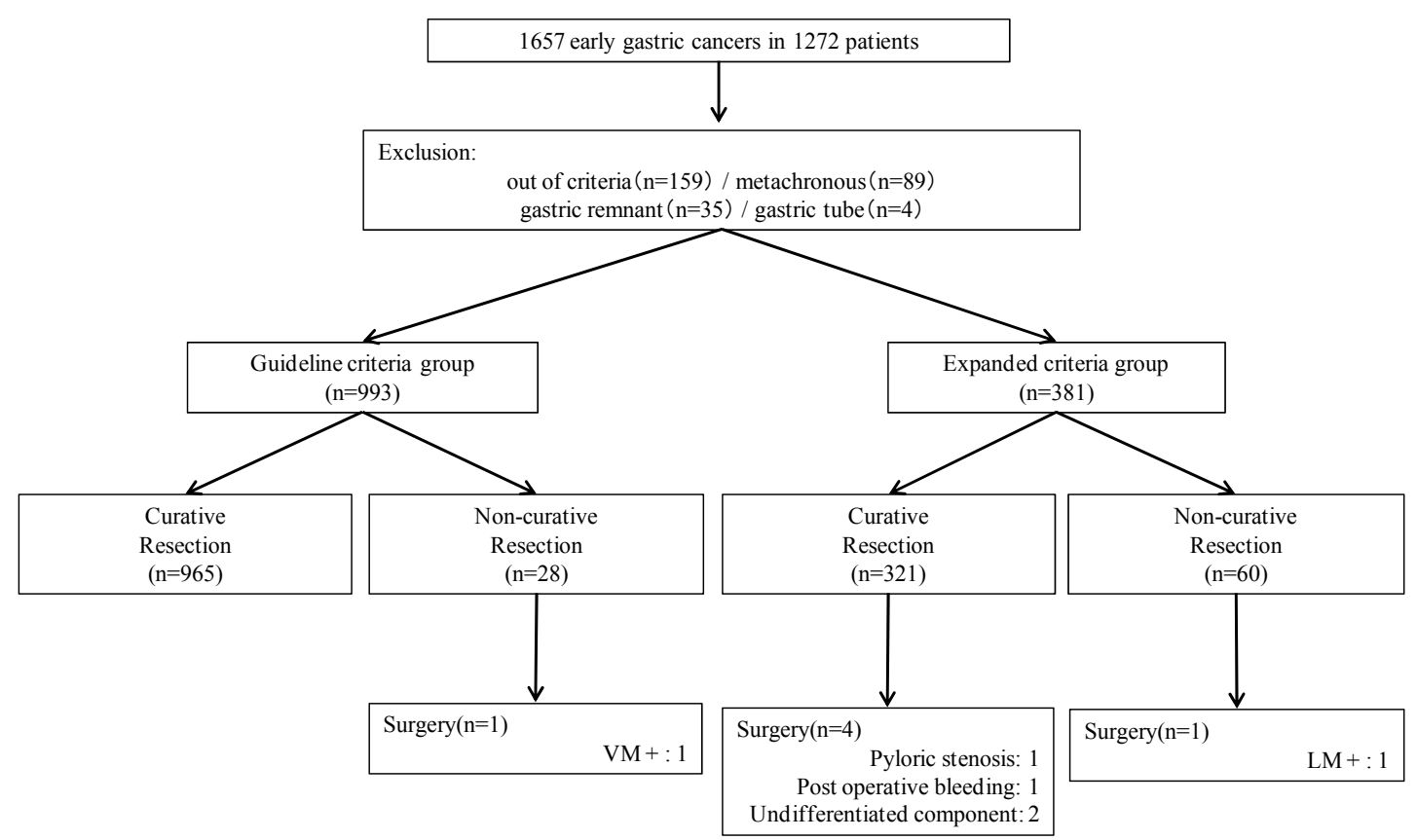

Figure 1. A flowchart showing the patients included in this study.

these patients underwent surgical treatment. There were 60 patients with non-curative resection of expanded-indication lesions. One of these patients underwent surgical treatment.

\subsection{Local Recurrence}

There was local recurrence in 10 lesions $(0.06 \%)$. All these cases had recurrence after non-curative resection. When ESD was performed again, 8 patients had curative resection. The remaining 2 patients had another recurrence and underwent surgery, but no lymph node metastasis was observed.

\subsection{Complications}

Among all patients, the incidence was $2.5 \%$ each for perforation and postoperative bleeding. There were no deaths related to the ESD procedure. For the guideline lesions, the incidence was $1.6 \%$ for perforation, and there were no cases that required surgical treatment. The incidence was also $1.8 \%$ for postoperative bleeding. For the expanded-indication ulcer-negative (expand, UL-) lesions, the incidence was $4.3 \%$ for perforation, and there was one surgically-treated case. The incidence was $3.9 \%$ for postoperative bleeding, and there were three patients who received blood transfusions. Surgical treatment and intervention radiology were each performed in one patient. For the expanded-indication ulcer-positive (expand, $\mathrm{UL}+$ ) lesions, the incidence was $4.3 \%$ each for perforation and postoperative bleeding. There were no statistically significant differences in any of these complications among the patients with different types of lesions. For the expanded-indication ulcer-negative (expand, UL-) lesions, one patient had a postoperative gastric emptying disorder and underwent surgical treatment (Tables 2 and 3).

\section{Discussion}

EMR is a conventional method used for early gastric cancer. However, it has the disadvantages of a low en bloc resection rate and limitation of the size of lesions that can be resected. ESD has gained interest as a technique without these disadvantages and has become widely used. The problems associated with ESD are the difficulty in training physicians, long procedure time, and rate of complications. However, these problems are being resolved. These reports might have included outcomes of ESD performed by experienced endoscopists. In our institution, ESD was introduced 10 years ago and there are 20 practitioners who have performed this procedure. If good outcomes of en bloc resection rate and rate of complications can be obtained by many non-experts, then ESD can be established as a standard treatment for early gastric cancer. In our study, the overall en bloc resection rate was $98.6 \%$ for all lesions, and the rate was $99.4 \%$ for the guideline lesions. In the guideline lesions (i.e., lesions $<20 \mathrm{~mm}$ and without ulcers), the incidence rates of complications were $1.8 \%$ and $1.6 \%$ for postoperative bleeding and perforation, respectively. Therefore, ESD can be safely used as a standard treatment for these lesions.

We use step-by-step early training to maintain these levels of outcomes. 1) Biopsy and hemostatic techniques 
can be performed; 2) There is an understanding of ESD indications and peripheral equipment; 3 ) The trainee has experience as an assistant in at least 20 cases. They has subsequently been trained using resected stomachs of pigs and performs partial resection in patients with the assistance of experienced endoscopists. Oda et al. [16] also described step-by-step training which was similar to our training conditions. They stated that the turning point of the learning curve was the experience of ESD in the lower third of the stomach in at least 30 cases.

Future studies of ESD should include examination of long-term outcomes after early gastric cancer treatment. In particular, it is necessary to examine the prognosis of expanded-indication lesions, [17,18] lesions of mixed histological type, [19] and poorly differentiated lesions [20]. In our study, we had information on the progress of $95.4 \%$ of all the subjects. No metastases related to the ESD sites were found in the cases that were followed up. There is an ongoing prospective study [21] of multiple cases at 41 institutions in Japan, and a five-year followup has been planned.

In conclusion, this study examined over 1000 cases of ESD for early gastric cancer performed at a single institution. ESD was shown to be safe and to have a good curative resection rate. These results suggest that ESD is suitable as an early gastric cancer treatment from the aspects of safety and efficacy. It can be considered a standard treatment for early gastric cancer.

\section{REFERENCES}

[1] M. Endo, M. Inomata, T. Terui, S. Oana, N. Kudara, H. Obara, Y. Hashimoto, T. Chiba, S. Orii and K. Suzuki. "New Endoscopic Technique to Close Large Mucosal Defects after Endoscopic Mucosal Resection in Patients with Gastric Mucosal Tumors," Digestive Endoscopy, Vol. 16, No. 4, 2004, pp. 372-375. doi:10.1111/j.1443-1661.2004.00410.x

[2] M. Endo, M. Higuchi, T. Chiba, K. Suzuki and Y. Inoue, "Present State of Endoscopic Hemostasis for Nonvariceal Upper Gastrointestinal Bleeding," Digestive Endoscopy, Vol. 22, No. 1, 2010, pp. 31-34. doi:10.1111/j.1443-1661.2010.00976.x

[3] S. Oka, S. Tanaka, I. Kaneko, R. Mouri, M. Hirata, T. Kawamura, M. Yoshihara and K. Chayama. "Advantage of Endoscopic Submucosal Dissection Compared with EMR for Early Gastric Cancer," Gastrointestinal Endoscopy, Vol. 64, No. 6, 2006, pp. 877-883. doi:10.1016/j.gie.2006.03.932

[4] I. Oda, D. Saito, M. Tada, H. Iishi, S. Tanabe, T. Oyama, T. Doi, Y. Otani, J. Fujisaki, Y. Ajioka, T. Hamada, H. Inoue, T. Gotoda and S. Yoshida, "A Multicenter Retrospective Study of Endoscopic Resection for Early Gastric Cancer," Gastric Cancer, Vol. 9, No. 4, 2006, pp. 262270. doi:10.1007/s10120-006-0389-0

[5] S. Nonaka, I. Oda, T. Nakaya, C. Kusano, H. Suzuki, S.
Yoshinaga, T. Fukagawa, H. Katai and T. Gotoda. "Clinical Impact of a Strategy Involving Endoscopic Submucosal Dissection for Early Gastric Cancer: Determining the Optimal Pathway," Gastric Cancer, Vol. 14, No. 1, 2011, pp. 56-62. doi:10.1007/s10120-011-0008-6

[6] J. Y. Ahn, H.-Y. Jung, K. D. Choi, J. Y. Choi, M.-Y. Kim, J. H. Lee, K.-S. Choi, D. H. Kim, H. J. Song, G. H. Lee, J.-H. Kim and Y. S. Park. "Endoscopic and Oncologic Outcomes after Endoscopic Resection for Early Gastric Cancer: 1370 Cases of Absolute and Extended Indications," Gastrointestinal Endoscopy, Vol. 74, No. 3, 2011, pp. 485-493. doi:10.1016/j.gie.2011.04.038

[7] J. S. Jang, S. R. Choi, W. Qureshi, M. C. Kim, S. J. Kim, J. S. Jeung, S. Y. Han, M. H. Noh, J. H. Lee, S. W. Lee, Y. H. Baek, S. H. Kim and P. J. Choi, "Long-Term Outcomes of Endoscopic Submucosal Dissection in Gastric Neoplastic Lesions at a Single Institution in South Korea," Scandinavian Journal of Gastroenterology, Vol. 44, No. 11, 2009, pp. 1315-1322. doi:10.3109/00365520903254304

[8] T. Sano and Y. Kodera, "Japanese Gastric Cancer Treatment Guidelines 2010 (Ver. 3)," Gastric Cancer, Vol. 14, No. 2, 2011, pp. 113-123. doi:10.1007/s10120-011-0042-4

[9] T. Gotoda, A. Yanagisawa, M. Sasako, H. Ono, Y. Nakanishi, T. Shimoda and Y. Kato, "Incidence of Lymph Node Metastasis from Early Gastric Cancer: Estimation with a Large Number of Cases at Two Large Centers," Gastric Cancer, Vol. 3, No. 4, 2000, pp. 219-225. doi:10.1007/PL00011720

[10] N. Yahagi, M. Fujishiro, N. Kakushima, K. Kobayashi, T. Hashimoto, M. Oka, M. Iguchi, S. Enomoto, M. Ichinose, H. Niwa and M. Omata, "Endoscopic Submucosal. Dissection for Early Gastric Cancer Using the Tip of an Electrosurgical Snare (Thin Type)," Digestive Endoscopy, Vol. 16, No. 1, 2004, pp. 34-38. doi:10.1111/j.1443-1661.2004.00313.x

[11] H. Yamamoto, T. Yube, N. Isoda, Y. Sato, Y. Sekine, T. Higashizawa, K. Ido, K. Kimura and N. Kanai, "A Novel Method of Endoscopic Mucosal Resection Using Sodium Hyaluronate," Gastrointestinal Endoscopy, Vol. 50, No. 2, 1999, pp. 251-256. doi:10.1016/S0016-5107(99)70234-8

[12] H. Ono, H. Kondo, T. Gotoda, K. Shirao, H. Yamaguchi, D. Saito, K. Hosokawa, T. Shimoda and S. Yoshida, "Endoscopic Mucosal Resection for Treatment of Early Gastric Cancer," Gut, Vol. 48, No. 2, 2001, pp. 225-229. doi:10.1136/gut.48.2.225

[13] H. Ono, N. Hasuike, T. Inui, K. Takizawa, H. Ikehara, Y. Yamaguchi, Y. Otake and H. Matsubayashi "Usefulness of a Novel Electrosurgical Knife, the Insulation-Tipped Diathermic Knife-2, for Endoscopic Submucosal Dissection of Early Gastric Cancer," Gastric Cancer, Vol. 11, No. 1, 2008, pp. 47-52. doi:10.1007/s10120-008-0452-0

[14] T. Oyama and Y. Kikuchi. "Aggressive Endoscopic Mucosal Resection in the Upper GI Tract-Hook Knife EMR Method," Minimally Invasive Therapy and Allied Technologies, Vol. 11, No. 5-6, 2002, pp. 291-295.

[15] T. Sano and Y. Kodera, "Japanese Classification of Gastric Carcinoma: 3rd English Edition," Gastric Cancer, 
Vol. 14, No. 2, 2011, pp. 101-112. doi:10.1007/s10120-011-0041-5

[16] I. Oda, T. Odagaki, H. Suzuki, S. Nonaka and S. Yoshinaga "Learning Curve for Endoscopic Submucosal Dissection of Early Gastric Cancer Based on Trainee Experience," Digestive Endoscopy, Vol. 24, No. 1, 2012, pp. 129-132. doi:10.1111/j.1443-1661.2012.01265.x

[17] T. Gotoda, M. Iwasaki, C. Kusano, S. Seewald and I. Oda "Endoscopic Resection of Early Gastric Cancer Treated by Guideline and Expanded National Cancer Centre Criteria," British Journal of Surgery, Vol. 97, No. 6, 2010, pp. 868-871. doi:10.1002/bjs.7033

[18] H. Lee, W. K. Yun, B. H. Min, J. H. Lee, P. L. Rhee, K. M. Kim, J. C. Rhee and J. J. Kim, “A Feasibility Study on the Expanded Indication for Endoscopic Submucosal Dissection of Early Gastric Cancer," Surgical Endoscopy, Vol. 25, No. 6, 2011, pp. 1985-1993. doi:10.1007/s00464-010-1499-7

[19] N. Hanaoka, S. Tanabe, T. Mikami, I. Okayasu and K.
Saigenji, "Mixed-Histologic-Type Submucosal Invasive Gastric Cancer as a Risk Factor for Lymph Node Metastasis: Feasibility of Endoscopic Submucosal Dissection," Endoscopy, Vol. 41, No. 5, 2009, pp. 427-432. doi:10.1055/s-0029-1214495

[20] K. Okada, J. Fujisaki, T. Yoshida, H. Ishikawa, T. Suganuma, A. Kasuga, M. Omae, A. Ishiyama, T. Hirasawa, A. Chino, M. Inamori, Y. Yamamoto, N. Yamamoto, T. Tsuchida, Y. Tamegai, A. Nakajima, E. Hoshino and M. Igarashi, "Long-Term Outcomes of Endoscopic Submucosal Dissection for Undifferentiated-Type Early Gastric Cancer," Endoscopy, Vol. 44, No. 2, 2012, pp. 122-127. doi:10.1055/s-0031-1291486

[21] I. Oda, T. Shimizu, H. Ono, S. Tanabe, H. Iishi, H. Kondo and M. Ninomiya, "Design of Japanese Multicenter Prospective Cohort Study of Endoscopic Resection for Early Gastric Cancer Using Web Registry (J-WEB/ EGC)," Gastric Cancer, Vol. 15, No. 4, 2012, pp. 451-454. doi:10.1007/s10120-012-0159-0 